\title{
Introdução à Criminologia Global: superando a crise da Criminologia Crítica
}

\section{Marina Quezado Soares}

Doutoranda em Direito e Ciência Política pela Universitat de Barcelona. Mestre em Direito, Estado e Constituição pela Universidade de Brasília (UnB). Bolsista CAPES. E-mail: marinaquezado@hotmail.com

\section{Resumo}

O objetivo do presente artigo é debater o futuro da Criminologia Crítica, introduzindo os caminhos que estão sendo delineados, desde a Universidade de Barcelona, rumo à revisão (ou ampliação) de seu objeto para uma Criminologia Global, em que a criminalidade de poder é tomada como foco principal da investigação criminológica e onde uma perspectiva desenvolvida a partir do conceito de "social harm" possibilita a retomada do projeto crítico em defesa dos direitos humanos.

Palavras-chave

Criminologia Crítica; Criminologia Global; Dano Social; Crise; Direitos Humanos.

\section{Introduction to Global Criminology: overcoming the crisis of Critical Criminology}

\footnotetext{
Abstract

The aim of this work is to recognize a crisis in Critical Criminology and to debate its future. In order to do so, it introduces the path currently developed at the University of Barcelona toward a Global Criminology, placing focus on the criminality of the powerful as the main object of criminological study, and using the concept of "social harm" to allow the resumption of the critical project for the defense of human rights.

Keywords

Critical Criminology; Global Criminology; Social Harm; Crisis; Human Rights.
} 


\section{Sumário}

Introdução. 1. A crise da Criminologia Crítica. 2. A perspectiva do "dano social" e a Zemiologia. 3. Rumo à Criminologia Global. Conclusão. Referências.

\section{Introdução}

Aqueles que estudam teoricamente a Criminologia Crítica, ${ }^{1}$ especialmente no Brasil, reconhecem as dificuldades que o marco teórico que recepcionaram dos Estados Unidos e Europa, desde finais dos anos 1970, sempre vivenciou e vivencia. Dentro de um contexto em que a consciência sobre as estruturas de poder, as relações de classe, gênero e raça e a crítica ao sistema penal altamente seletivo ainda fazem todo o sentido em nível teórico, discute-se a crise da Criminologia Crítica e seu próprio futuro, diante de suas importantes limitações para lidar com o aumento da cultura punitiva, a expansão do sistema penal e a violência estrutural no mundo hoje.

Na tentativa de superação desse momento vivido pela Criminologia Crítica, Carolina Costa Ferreira, em recente artigo (2016), fez a revisão bibliográfica dos principais autores e ideias do movimento para reafirmar que remanesce sua "função provocadora, de desconstrução de questões postas ou tidas por "solucionadas" e de sua importância como "instrumento de questionamento da desigualdade e inoperância do sistema penal, da estrutura de classes, e de desenvolvimento de propostas", convocando para a ida a campo e para o "enfrentamento" aos discursos punitivos.

Vera Regina Pereira Andrade, homenageando Juarez Cirino dos Santos (2012), apressou-se em contestar que a Criminologia Crítica, "ao contrário do que proclamaram e proclamam leitores apressados, não está morta", mas não deixou de expressar sua angústia, resgatada por Carolina Ferreira (2016, p. 189), de que os pensamentos criminológicos críticos atuais limitem-se à crítica sobre o funcionamento do sistema penal - e consequente inconstitucionalidade de sua atuação - e não avancem a medidas descarcerizantes, descriminalizadoras e, principalmente, abolidoras do próprio sistema penal.

É inegável reconhecer, assim, em muitos acadêmicos críticos, a consciência sobre esse momento de crise, de estagnação da disciplina, de desânimo e de incertezas sobre

\footnotetext{
${ }^{1}$ Não se desconhece a preferência pela utilização do termo "Criminologias críticas", no plural, mais adequado à faceta multidimensional das várias teorias críticas que se dessenvolveram nessa direção. Entretanto, adota-se, neste texto, o termo "Criminologia Crítica", no singular, no sentido de "movimento criminológico" - como marcado, entre outros autores, por Vera Regina Pereira de Andrade (2012) e por Carolina Costa Ferreira (2016) - que surgiu no final dos anos 1960 e início de 1970, nos Estados Unidos e Inglaterra, e se desenvolveu no eixo Euroamericano (na Alemanha, Itália, Espanha, Holanda, França, Países Nórdicos, Canadá) e, enfim, na América Latina, em franca oposição à Criminologia Positivista.
} 
que Criminologia se fará daqui para frente. Desde a mudança paradigmática em Criminologia e o desenvolvimento da perspectiva crítica, os tantos acontecimentos que ocorreram em nível mundial tornaram ainda mais necessário um debate sobre seu rumo.

Nas palavras de Iñaki Rivera Beiras² $(2014$, p. 6):

[...] a transformação geopolítica que supôs o desaparecimento de alguns dos antigos blocos políticos, a desintegração da URSS, a queda do muro de Berlim, o início da chamada "globalização" econômica, o desenvolvimento de novas tecnologias que transformavam muito mais que as meras comunicações, os atentados do 11 de setembro de 2001 (e os outros posteriores), o início de uma ofensiva bélica de luta contra um inimigo em escala internacional [...] convocavam, no particular universo das ciências sociais e penais, a um imprescindível debate e atualização dos conteúdos disciplinares arraigados em estruturas que estavam sendo abruptamente modificadas. $^{3}$

O objetivo do presente artigo é, portanto, reconhecer esse momento para debater o futuro e, nesse debate, apresentar os caminhos que estão sendo delineados rumo à revisão (ou ampliação) do objeto da Criminologia Crítica, para uma Criminologia Global.

\section{A crise da Criminologia Crítica}

Para desenhar um futuro possível para a Criminologia Crítica, como afirma Swaaninger (1999), é preciso, primeiro, analisar como ela entrou em crise.

É correto afirmar que, historicamente, a Criminologia Crítica praticamente nasceu em crise: tendo como obra que marca seu surgimento o livro "New Criminology", de Taylor, Walton e Young, de 1973, já em 1980 se afirmava seu estado de crise (Melossi, 1985). Em 1983, Dario Melossi (1985) defendia, no Nono Congresso Internacional de Criminologia, em Vienna, a tese de que a Criminologia Crítica vivia uma crise de fundo eminentemente teórico decorrente das críticas que direcionou, após a oposição feita às

\footnotetext{
${ }^{2}$ As citações em língua estrangeira, reproduzidas no presente artigo, estão traduzidas pela autora, livremente, para o português. $O$ trecho na língua original da publicação será reproduzido em nota de rodapé.

3 "Eran muchos los sucesos de gran trascendencia mundial que habían acontecido en las últimas décadas. La transformación geopolítica que suponía la desaparición de alguno de los antiguos bloques políticos, la desintegración de la URSS, la caída del muro de Berlín, el inicio de la llamada «globalización» económica, el desarrollo de las nuevas tecnologías que transformaban mucho más que las meras comunicaciones, los atentados del 11 de septiembre de 2001 (y otros posteriores), el inicio de una ofensiva bélica de lucha contra un enemigo a escala internacional, por citar tan solo algunos acontecimientos de relieve mundial y reciente; convocaban, en el particular universo de las ciencias sociales y penales, a un imprescindible debate y re-actualización de unos contenidos disciplinares anquilosados en unas estructuras que estaban siendo abruptamente modificadas." (RIVERA BEIRAS, 2014, p. 6).
} 
pressuposições criminológicas legalistas e psiquiátricas das Escolas Clássica e Positiva, à criminologia sociológica de matriz interacionista.

Ou seja, as iniciais críticas ao labeling approach feitas pelos primeiros criminólogos críticos representavam, para Melossi (1985, p. 203), o clássico exemplo do "bebê que é jogado fora junto com a água da bacia", por isso, alinhando-se a Alessandro Baratta, ressaltava que a Criminologia Crítica deveria desenvolver-se pela conjunção da "dimensão da definição" e da "dimensão de poder", mostrando que não era necessária, portanto, a rejeição das teorias interacionistas que a precederam.

A primeira crise da Criminologia Crítica, assim, ocorreu a partir da discussão de sua compatibilização com o labeling approach: de um lado os que viam a teoria do etiquetamento como uma teoria limitada, que desconsiderava as relações de poder existentes na sociedade e, de outro, os que reconheciam sua importante contribuição no câmbio paradigmático em criminologia. ${ }^{4}$

Um segundo momento de crise pode ser identificado com o advento, na década de 1980, do movimento de lei e ordem (que, por exemplo, foi o carro-chefe do Partido Conservador na Inglaterra, nas eleições de 1979) e, com ele, uma Criminologia que John Tierney (2006, p. 218, 235) chama de “New Right". Essa Criminologia “de direita” não se estabeleceu como uma escola de pensamento homogêneo, mas expressou-se em torno a temas-chave, através de ataques às políticas criminais que entendiam haver fracassado e adoção de práticas baseadas no senso comum, e justificou um momento expansionista do sistema penal tanto na Europa quanto nos Estados Unidos. Aliado a isso, sobreveio um interesse renovado na Criminologia Positivista, paradigma que retornava forte onde havia sido superado, pelas teorias interacionistas e da rotulação, e que, no Brasil, ainda dominava a abordagem criminal.

A terceira grande crise decorreu da queda do Muro de Berlim e, com ela, a perda gradual das perspectivas utópicas de reestruturação da sociedade, a crença em um mundo justo no futuro, tornando a conexão da Criminologia Crítica com o marxismo alvo de duro questionamento:

A imagem marxista da Criminologia Crítica, depois da queda do Muro de Berlim, em 1989, se tornou um pouco complicada. Como crítica social, o materialismo histórico pode ainda fazer muito sentido na maioria dos lugares

${ }^{4}$ Essa crise inicial teórica foi superada e a criminologia crítica se estabeleceu "como uma perspectiva criminológica orientada pelo materialismo (método) que, ao incorporar os avanços das teorias rotulacionistas e conflituais, refuta os modelos consensuais de sociedade e os pressupostos causais explicativos da criminalidade de base microssociológica (criminologia ortodoxa) e redireciona o objeto de investigação aos processos de criminalização, à atuação das agências do sistema penal e, sobretudo, às relações entre estrutura política e controle social." (CARVALHO, 2013, p. 4).

Revista Publicum

Rio de Janeiro, v. 3, n. 1, 2017, p. 190-208.

http://www.e-publicacoes.uerj.br/index.php/publicum

DOI: 10.12957/publicum.2017.28920 
do mundo, mas como estratégia política, ou ainda como um modelo de sociedade, é largamente considerado como algo que um dia foi, mas que nunca retornará. ${ }^{5}$ (SWAANINGEN, 1999, p. 15).

Apesar do impacto que pode ter tido no projeto utópico dos criminólogos críticos, estes permaneceram firmes em separar o fato histórico das bases teóricas do movimento: declarar a morte da Criminologia Crítica a partir dele é "erroneamente, tomar a parte (contexto fundacional de movimento) pelo todo (processo), equivalendo à declaração da morte do socialismo como utopia (processo) à queda do Muro de Berlim (contexto)." (ANDRADE, 2012, p. 144-145).

Ademais, de nenhuma maneira o projeto político criminológico crítico se perdeu, ele apenas se adaptou. A Criminologia Crítica teve suas raízes no que Tierney (2006, p. $339,347)$ chama de "neo-Marxismo", o que permitiu analisar o capitalismo e situar crime, desvio e controle social dentro desta análise, em rumo inegável à sua finalização como modelo econômico e de sociedade e sua substituição pelo socialismo. Com a expansão do capitalismo pós-1980 em nível global, o foco dos criminólogos críticos contemporâneos passou a ser mais o mercado neoliberal desenfreado, que o capitalismo em si. ${ }^{6}$

Paralelamente a isso, se indagava se os criminólogos críticos teriam negligenciado os problemas sociais reais das cidades, cujo enfrentamento sempre viria virtualmente impregnado com a ideia de intervenção repressiva, racista e direcionada às classes baixas (SWAANINGEN, 1999, p. 15). Essa preocupação por uma abordagem alternativa e não estigmatizante do crime acabou por incitar, também, uma ampliação do controle social de maneira distinta do projeto criminológico crítico inicial, com a adoção de medidas de política criminal que acabaram por dar espaço à reinvenção da criminologia tradicional em forma de uma Criminologia Administrativista, ou atuarial, voltada à prevenção do crime e gerenciamento do risco.

5 "Critical criminology's Marxist image has, particularly after the fall of the Berlin Wall in 1989, become quite complicated. As a social critique, historical materialism may still make a lot of sense in most parts of the world, but as a political strategy, or indeed as a model of society, it is widely regarded as something which one was, but is never to return. (SWAANINGEN, 1999, p. 15).

6 "For neo-Marxist critical criminologists the ultimate goal was the achievement of socialism (or communism), though what was meant by a socialist (or communist) society was by no means agreed upon. Although 'socialism' is still referred to among critical criminologists (and even among New Labour cabinet ministers), its ideological power has, over the last quarter of a century, been hugely diminished. Furthermore, large-scale, radical social movements in, for example, Europe and North America, now mobilise around issues of globalisation and environmentalism, rather than socialism understandable given the collapse of (state) socialism around the world, and its track record of oppression and environmental degradation. Whilst the raison d'être of critical criminology continues to be a commitment to critique oriented explicitly towards the realisation of a more equal and just society, there is now: 'the problem of the narrative which guides such a transformation' [...]" (TIERNEY, p. 340). 
A crise da Criminologia Crítica seguiu em pauta e, em 1991, durante os encontros da "Law and Society" em Amsterdam, organizados por Stan Cohen, Willem de Haan, Elena Larrari, Fritz Sack e Karl Schumann, com participação de vários criminólogos, entre eles Dario Melossi e Carol Smart, uma tentativa de avaliação dessa crise foi feita. Nesses encontros, se propôs avaliar, no exame das particularidades de transferir os conceitos críticos para as diversas culturas, quais conceitos da Criminologia Crítica necessitariam revisão, quais deveriam ser esquecidos e quais mantinham sua validade (SWAANINGEN; TAYLOR, 1994, p. 183-184).

A iniciativa de 1991 foi retomada por Guiseppe Mosconi, Rene van Swaaningen e Ian Taylor ${ }^{7}$ na 20a Conferência do Grupo Europeu para o Estudo do Desvio e do Controle Social (The European Group for the Study of Deviance and Social Control), em setembro de 1992, em Pádua, Itália, quando se organizou, no último dia da conferência, um workshop sobre "O Futuro da Criminologia Crítica". Rene van Swaaningen presidiu o painel integrado por John Lea (Middlesex, England), Maeve McMahon (Toronto), Pio Marconi (Rome), Guiseppe Mosconi (Padua), Massimo Pavarini (Bologna), Eligio Resta (Bari), Vincenzo Ruggiero (Middlesex, England/Torino) e lan Taylor (Salford, England) para debater a trajetória da Criminologia Crítica na última década do século XX (SWAANINGEN; TAYLOR, 1994, p. 185). Os participantes do painel se dividiam entre os que identificavam problemas no projeto criminológico crítico que impediam o enfrentamento da criminalidade, os que reafirmavam a desnecessidade de sua revisão e os que expressavam sua total decepção com os rumos do movimento.

Esses três grupos podiam representar bem como a Criminologia Crítica chegou à contemporaneidade: entre os que partiram para o realismo de esquerda ${ }^{8}$ ou questionaram firmemente a compatibilidade dessa Criminologia com suas aspirações, como foi o caso do feminismo, os que desenvolveram políticas criminais (de alguma maneira em contradição de fundo com o próprio movimento como foi concebido), como foi o garantismo penal, ou os que mantiveram a utopia de mudança na sociedade e no sistema penal através de sua abolição.

\footnotetext{
${ }^{7}$ Rene Van Swaaningen e lan Taylor, em 1994, publicaram um relato interessante sobre o debate acerca da crise da Criminologia Crítica, no contexto europeu, que impelia a discussão sobre a própria viabilidade do projeto criminológico crítico no contexto mundial pós 1984.

8 O realismo de esquerda, nas palavras de John Tierney (2003, p. 234), foi uma "tentativa de construir uma criminologia crítica que estivesse preparada para abordar tanto as causas do crime quanto elaborar políticas práticas destinadas a reduzir a vitimização de setores vulneráveis da sociedade". "Left realism represented an attempt to construct a radical criminology that was prepared to address both the causes of crime and practical policies aimed at reducing the victimisation of vulnerable sections of society".
}

Revista Publicum

Rio de Janeiro, v. 3, n. 1, 2017, p. 190-208.

http://www.e-publicacoes.uerj.br/index.php/publicum

DOI: 10.12957/publicum.2017.28920 
Na América Latina, onde o movimento crítico foi recepcionado como movimento de resistência para combater o discurso punitivo, a violência e o racismo e que seguiu, por muito tempo, lutando contra a dominância das noções do paradigma positivista incorporados no sistema penal e tentando estabelecer uma teoria autenticamente latinoamericana, a crise da Criminologia Crítica chegou de maneira tardia porque, certamente, reconhecer uma crise ao mesmo tempo que a teoria era recepcionada seria enfraquecer a única opção de partida disponível para discutir, criticamente, as violências estruturais e institucionais que envolviam a questão do controle e do desvio naquela realidade.

Assim, o questionamento que se fazia na América Latina não era intrínseco à Criminologia Crítica, mas relativo a seu contraponto com a Criminologia Tradicional. Discutia-se se, para o contexto latino-americano, era conveniente manter a nova disciplina dentro da Criminologia, sempre etiológica, ou se se deveria tratá-la como sociologia jurídico-penal, que teria como objeto não o crime, mas a "questão criminal", como já se defendia na Itália por Baratta e Bergalli (ANITUA, 2015, p. 34).

Passados mais de quarenta anos, a crise do movimento crítico na América Latina decorre do que Camilo Ernesto Bernal Sarmiento, Sebastián Cabezas Chamorro, Alejandro Forero Cuéllar, Iñaki Rivera Beiras e Iván Vidal Tamayo, citando Massimo Sozo (2014, p. 3536), chamam de uma cristalização ocorrida nos principais argumentos e enfoques da Criminologia Crítica:

Após a ruptura epistemológica que supôs a desmistificação do paradigma causalista por parte da criminologia crítica na década de 1970 e de sua posterior expansão no continente durante a década seguinte, se registraram outros momentos-chave na discussão epistemológica desta área de saberpoder sobre a questão criminal. O primeiro, em meados da década de 1980, concentrou-se no debate promovido por vários acadêmicos sobre as necessárias relações entre criminologia e direito penal e o papel que essas disciplinas deviam cumprir na investigação e eventual transformação das formas de controle punitivo presentes nas sociedades latino-americanas (Novoa Monreal, 1985; Aniyar de Castro, 1986; Novoa Monreal, 1986; Bergalli, 1986; Olmo, 1987). O segundo, que se produziu desde finais da década de 1980 e durante boa parte da década seguinte, estava relacionado com o processo de tradução, incorporação cultural e adaptação local dos fundamentos conceituais e das propostas político-criminais de duas tendências da criminologia crítica: o abolicionismo e o direito penal mínimo ou o garantismo penal (Martínez Sánchez, 1995; Zaffaroni, 1998; Sotomayor Acosta, 2006; Sozzo, 2006). Depois destes momentos é difícil encontrar outros pontos de inflexão no pensamento criminológico crítico continental, registrando-se, melhor, uma possível "cristalização" de seus principais argumentos e enfoques (Sozzo, 2006, pp. 414 y ss.). ${ }^{9}$

9 "Luego de la ruptura epistemológica que supuso la desmitificación del paradigma causalista por parte de la criminología crítica en la década de 1970 y de su posterior expansión en el continente durante la década siguiente, se han registrado otros dos momentos claves en la discusión epistemológica de esta área de saber-poder sobre la cuestión criminal. El primero, a mediados de la

Revista Publicum

Rio de Janeiro, v. 3, n. 1, 2017, p. 190-208.

http://www.e-publicacoes.uerj.br/index.php/publicum

DOI: $10.12957 /$ publicum.2017.28920 
De vários matizes e de maneira permanente, o debate sobre as "crises" da Criminologia Crítica está vivo. As crises ora foram superadas, ora deram margem a críticas e tentativas de sua própria superação, e, certamente, a que se enfrenta agora não é a mesma esboçada nos anos 1980.

A "cristalização" que se vê na Criminologia Crítica latino-americana alia-se, hoje, à dificuldade de enfretamento dos novos temas emergentes no resto do mundo. Hil e Robertson (2003, p.97), resgatando mais uma conferência realizada para discutir o futuro da Criminologia Crítica, desta vez realizada na Universidade de Western Sydney, Austrália, em fevereiro de 2001, com criminólogos da Inglaterra, Austrália e Nova Zelândia, ilustraram, com ela, a incapacidade que a Criminologia Crítica já mostrava, desde então, em lidar com as transformações pelas quais o mundo estava passando e com os novos desafios gerados pela Criminologia Administrativa, pela cultura neoliberal do controle do crime e pela ideologia atuarial.

Para esses autores, ao focar tão fortemente no controle do crime per si e se afastar de muitas das agendas políticas das primeiras versões das análises radicais, a Criminologia Crítica direcionou-se a uma análise excessivamente descritiva do que que "é", em vez de posições mais prescritivas sobre o que "deveria ser" (HIL; ROBERTSON, 2003, p. 99-100). Essa tendência se mostrou na referida conferência que foi de interesse, nas palavras dos autores, não pelo que abordou, mas pelo que omitiu em suas deliberações. Quase exclusivamente trataram da revisão analítica e atualização sobre pesquisas feitas, sem enfrentamento das grandes questões associadas com os arranjos neoliberais ou estabelecimento de objetivos para perseguir a justiça social, dando notas da verdadeira estagnação do pensamento criminológico crítico.

As novas demandas que se apresentam à Criminologia Crítica, por exemplo, lidar com a cultura neoliberal do controle do crime, com a ideologia atuarial, o surgimento das racionalidades burocráticas no campo penal, seu uso excepcional, a tolerância zero e o

década de 1980 se concentró en un debate promovido por varios académicos/as acerca de las necesarias relaciones entre la criminología y el derecho penal y el rol que estas disciplinas debían cumplir en la investigación y eventual transformación de las formas de control punitivo presentes en las sociedades latinoamericanas (Novoa Monreal, 1985; Aniyar de Castro, 1986; Novoa Monreal, 1986; Bergalli, 1986; Olmo, 1987). El segundo, que se produjo desde finales de la década de 1980 y durante buen parte de la década siguiente, estaba relacionado con el proceso de traducción, incorporación cultural y adaptación local de los fundamentos conceptuales y las propuestas político criminales de dos tendencias de la criminología crítica, el abolicionismo y el derecho penal mínimo o garantismo penal (Martínez Sánchez, 1995; Zaffaroni, 1998; Sotomayor Acosta, 2006; Sozzo, 2006). Más allá de estos momentos es difícil encontrar otros puntos de inflexión en el pensamiento criminológico crítico continental, registrándose más bien una posible "cristalización» de sus principales argumentos y enfoques (Sozzo, 2006, pp. 414 y ss.)." (BERNAL SARMIENTO, et.al., 2014, p. 35-36). 
direito penal do inimigo, não permitem que se mantenha assim "cristalizada" e o debate mais uma vez avança para sua definitiva reconfiguração.

Uma discussão importante e recente, nesse sentido, está ocorrendo entre criminólogos latino-americanos, desde a Universidade de Barcelona, na Espanha, através da incorporação de novas orientações criminológicas relacionadas com o estudo dos crimes de Estado, o genocídio e os danos sociais e de larga escala, rumo a uma Criminologia Crítica Global. Ela está sendo desenvolvida, entre outros, por Iñaki Rivera Beiras (2016, p. 26) a partir de três categorias epistemológicas como base: o conceito de violência estrutural como fundamento dos direitos humanos através da teoria das necessidades de Alessandro Baratta; a categoria sociológica da memória coletiva, útil para documentar a barbárie dos crimes dos Estados e dos mercados e impedir sua impunidade; e, por fim, a categoria de "dano social", como o elemento que permite transcender as considerações penais e criminológicas tradicionais.

Como afirma Rivera Beiras (2016, p. 36-38), trata-se de reformular o conteúdo epistemológico da Criminologia, na direção crítica e em uma dimensão global, reconhecendo, com Jock Young, a relevância "maior que nunca antes" da Criminologia crítica:

Creio firmemente que a criminologia crítica tem mais relevância agora que nunca antes e que a atitude crítica encaixa com a experiência da modernidade tardia... somos uns privilegiados ao poder trabalhar em um campo que investiga as dissociações fundamentais da justiça estendidas a todos os elos da ordem social, um campo para a ironia e a disputa, para a vituperação e a transgressão. Aqueles que pretendem marginalizar a criminologia crítica erram ao não compreender a importância da mesma na realidade social, aqueles em nosso campo de estudo que pretendem depreciar a palavra "crítica" e reduzi-la ao sectário ou esotérico, não chegam a compreender a posição central da crítica para neutralizar o neoliberalismo e suas formas de controle discursivo. Assim, ponhamos mãos à obra, sem esquecer a imperiosa necessidade de ser a oposição, analisemos sempre com um olhar irônico e satírico as estranhas divagações dos "dadossauros" e a triste farsa científica representada diante de nós, mas antes de tudo, tenhamos sempre presente a criatividade inerente à cultura humana, o ímpeto emocional e sentimental que nos constitui como humanos e a capacidade para a imaginação que ele engendra e exige. ${ }^{10}$ (YOUNG apud RIVEIRA BEIRAS, 2016, p. 36-38).

10 “Creo firmemente que la criminología crítica tiene más relevancia ahora que nunca antes y que la actitud crítica encaja con la experiencia de la modernidad tardía... somos unos privilegiados al poder trabajar en un campo que investiga las disociaciones fundamentales de la justica extendidas a todos los eslabones del orden social, un campo para la ironía y la disputa, para la vituperación y la trasgresión. Aquellos que pretenden marginalizar la criminología crítica erran al no comprender la importancia de la misma en la realidad social, aquellos en nuestro campo de estudio que pretenden depreciar la palabra "crítica" y reducirla a lo sectario o esotérico, no llegan a comprender la posición central de la crítica para contrarrestar el neoliberalismo y sus formas de control discursivo. Así que pongámonos manos a la obra, sin olvidar la imperiosa necesidad de ser la oposición, analicemos 
Assim, não se trata, aqui, de abandonar, mas de regenerar o projeto criminológico crítico, buscar novas ferramentas e refrescar e recuperar as antigas. Como explicam Bernal Sarmiento, et al. (2014, p. 62), o que se introduz com o presente artigo é a postulação de ideias de "como seguir utilizando a criminologia e como prosseguir, inclusive, apesar dela". 11

\section{A perspectiva do "dano social" e a Zemiologia}

Uma das principais constatações que impeliram a discussão rumo à Criminologia Crítica Global foi a de que a criminologia, ao concentrar-se excessivamente nos delitos comuns, deixou de cuidar da criminalidade massiva e dos atos (e omissões) que acarretam grande dano social, como os genocídios, os crimes de guerra e de lesa humanidade (RIVERA BEIRAS, 2016, p. 34), embora, já há muito, vários criminólogos críticos chamam a atenção para os crimes estatais, os delitos dos poderosos e as violações de direitos humanos como os mais danosos socialmente (BERNAL SARMIENTO et al., 2014, p. 48, 57).

A categoria de dano social (social harm) é a categoria que permite dar o impulso necessário para romper com as limitações da teoria criminológica, para que se deixe de falar em delito e castigo e se passe à perspectiva do dano social como objeto de estudo. Essa categoria foi promovida, principalmente, desde o Centro para o Estudo da Pobreza e da Justiça Social da Universidade de Bristol, Inglaterra, quando Paddy Hillyard era seu diretor.

Referido Centro promoveu, nos dias 12 e 13 de fevereiro de 1999, uma Conferência em Dartington, sul da Inglaterra, intitulada "Zemiology: Beyond Criminology?"12, com quatro objetivos principais: a) explorar o potencial de mover-se da análise do crime para o estudo do dano, definir dano, os contextos em que ocorriam mais frequentemente, seus

siempre con una mirada irónica y satírica las extrañas divagaciones de los "datosaurios" y la triste farsa científica representada frente a nosotros, pero ante todo, tengamos siempre presente la creatividad inherente a la cultura humana, el ímpetu emocional y sentimental que nos constituye como humanos y la capacidad para la imaginación que este engendra y exige". (YOUNG apud RIVEIRA BEIRAS, 2016, p. 36-38).

11 "Y como el modelo alternativo generado por el discurso crítico criminológico parece desde los años de 1980 totalmente acorralado por el managerialismo y la inercia de las prácticas inspiradas en el positivismo, la regeneración del proyecto pasa necesariamente por buscar nuevas herramientas o refrescar y recuperar las viejas. De manera sintética, lo que sigue será una postulación de estas ideas, de cómo seguir utilizando la criminología, y cómo continuar, incluso a pesar de ella." (BERNAL SARMIENTO, et al., 2014, p.62).

12 <http://www.radstats.org.uk/no070/conference2.htm>. Acesso em 11 abr. 2017. 
padrões e extensões e as características das pessoas que mais o sofriam; b) entender por que a criminologia era tão impermeável às críticas que lhe eram feitas há tantos anos: a questão da realidade ontológica (inexistente) do crime e o fato de que a maioria dos eventos que o sistema de justiça criminal lidava não tinha impacto tão severo na vida das pessoas e que os que realmente causavam sérios danos ou deveriam estar abrangidos pelo sistema eram ignorados ou tratados em outras esferas; $c$ ) explorar se a nova abordagem ajudaria a desenvolver respostas políticas mais abrangentes e finalmente efetivas sobre o dano experimentado pelas pessoas durante suas vidas; d) discutir a viabilidade e o potencial de uma abordagem organizada em torno do conceito de dano social, sua capacidade de desafiar o paradigma criminológico, de levar a uma mudança na ênfase a eventos considerados danosos, à redução da criminalização.

No ano de 2004, Hillyard, Pantazis, Tombs, e Gordon, publicaram o livro "Beyond criminology: Taking harm seriously", propondo o abandono da Criminologia em favor da Zemiologia (do grego "zemia", que quer dizer dano) ou "study of harm". Essa obra impeliu o debate sobre as críticas que essa perspectiva fazia à Criminologia. Com a publicação do livro, organizaram-se encontros na American Society of Criminology, em 2006, para sua discussão e, em 2007, a revista “Crime, Law and Social Change” publicou, em seu volume 48, uma edição especial sobre "Social Harm", em que os seus editores - David O. Friedrichs e Martin D. Schwartz (2007, p. 5-6) - reconheciam que a teoria merecia uma atenção especial e poderia, de fato, ser o futuro da Criminologia Crítica.

Hillyard e Tombs ([2004], 2013, p. 184-185), na construção do que seria a definição de "dano social", elencaram algumas de suas modalidades, que deveriam ser abarcadas pela nova disciplina, em termos exemplificativos: a) danos físicos (morte prematura ou lesões graves decorrentes de erros médicos, acidentes de tráfico e de trabalho, exposição a contaminantes do meio-ambiente, doenças, falta de alimentação ou moradia adequadas, morte, tortura e abusos praticados por funcionários estatais); b) danos financeiros/econômicos (pobreza e as distintas formas de perda de bens e dinheiro, particularmente em uma variedade de formas de fraude, apropriação indevida de fundos por parte de governos, empresas ou particulares, aumento de preços de bens e serviços por cartelização e acordos de fixação de preços, redistribuição de riqueza); c) danos emocionais e psicológicos; d) danos contra a segurança cultural (relacionados à autonomia, do desenvolvimento, o crescimento, o acesso a recursos culturais, intelectuais e a recursos de informação).

Simon Pemberton (2007, p. 36), que fez sua tese doutoral sobre o tema, explica que o conceito de "social harm" é preferível ao de zemiologia (estudo do dano), porque 
considera o termo "social" o mais importante da nova disciplina. Distingue, assim, os danos causados pelo mundo físico daqueles que resultam dos modos de organização social e explica que, politicamente, essa distinção é muito importante, uma vez que, dada a dominância global do capitalismo, o foco deve estar na identificação das relações danosas comuns às sociedades capitalistas. Pemberton considera que há duas formas de injustiça nas sociedades capitalistas: as socioeconômicas e as culturais, com danos provenientes das relações de produção e das relações de gênero e raça e que, partindo de que um indivíduo sofre dano quando suas necessidades não são atendidas, há várias situações de dano que são negligenciadas pela criminologia e poderiam ser consideradas pela perspectiva do dano social.

Ainda que as definições estejam em construção, o certo é que trabalhar com as ações ou omissões que geram dano social, para além das condutas previstas como crime na lei penal, permite uma série de benefícios. Hillyard e Tombs (2013, p. 186-189) relacionam vários, como, por exemplo, a possibilidade de desenvolver uma ideia mais precisa sobre o que realmente afeta a vida das pessoas, em contraposição com a imagem distorcida de dano que é produzida pela ideia de crime; ou a possibilidade de enfocar danos crônicos e vividos por muitas pessoas, como a exposição à contaminação do ar, a riscos à saúde no trabalho, à má alimentação, à moradia inadequada, ao desemprego, à violência estatal, em contraposição aos eventos discretos aos quais se direcionam a Criminologia e o Direito Penal. Além disso, o estudo do dano permite uma investigação mais ampla sobre seus responsáveis, ultrapassando a mera responsabilização individual, e permite buscar políticas de redução de danos e respostas outras que as estatais de vingança e castigo.

No entender de Hil e Robertson (2003, p. 97), as análises zemiológicas desde o conceito de "social harm" ofereceriam uma possibilidade melhor do que as realizadas pela Criminologia Crítica para entender a natureza e o significado das transformações no mundo de hoje e seus efeitos em vários aspectos sociais contemporâneos e seriam mais capazes de engajar a perspectiva de direitos humanos para além da lei penal ou da cultura de controle do crime.

Esse foco de análise já está sendo adotado, no Brasil, a exemplo das investigações realizadas por Marília De Nardin Budó (2016, p. 137), na área de "Green Criminology", quando, a respeito dos danos causados pelo amianto, afirmou:

O dano social aparece como um objeto de profundas possibilidades analíticas quando se pensa epistemologicamente na criminologia. Trata-se de permitir que as mortes mais numerosas e invisíveis possam aparecer, além de as vozes 
que estão silenciadas por detrás delas - de familiares de vítimas, de associações de afetados, de organizações não-governamentais, e mesmo de cientistas contrapostos à lógica do mercado - possam recuperar a capacidade de emitirem um grito de resistência perante os gigantes sem nome e sem face que provocam tanto sofrimento. Garantir que a criminologia não perca os poderosos de vista, sobretudo na relação entre Estados e Mercados, é o primeiro passo na compreensão desses danos gigantescos por eles causados, e, simultaneamente, na busca pelas alternativas a esse sistema.

Pela perspectiva do dano social, crime seria, apenas, um de seus vários aspectos e os criminólogos críticos seriam encorajados a enfrentar as injustiças em vários níveis institucionais, deixando as meras descrições sobre as ocorrências no controle do crime e direcionando-se para questionar a persecução desde o ponto de vista dos direitos humanos (HIL; ROBERTSON, 2003, p. 100). Como explica Pemberton (2007, p. 33): “O papel da perspectiva do dano social é ajudar a criar espaços discursivos onde os marginalizados possam articular sua vivida experiência de dano fora da persistente referência à noção de "crime". ${ }^{13}$

\section{Rumo à Criminologia Global}

Nesse contexto de novos caminhos para a discussão epistemológica da Criminologia, investigadores ligados ao OSPDH - Observatório do Sistema Penal e Direitos Humanos da Universidade de Barcelona, na Espanha, iniciaram seu debate, nesse sentido, a partir do aporte que fez Eugenio Raúl Zaffaroni"14 ao apresentar-lhes a obra "Criminology, Civilisation, and the New World Order", do criminólogo neozelandês Wayne Morrison.

Esse livro, publicado em inglês em 2006, foi traduzido para o castelhano em 2012 por iniciativa do grupo liderado por Iñaki Rivera Beiras ${ }^{15}$, que reconheceu, nesse trabalho, sua capacidade de apresentar propostas e enfoques “inquietantes e profundamente interpeladores" para o debate criminológico ${ }^{16}$ :

13 "The role of the social harm perspective is to help create the discursive spaces where the marginalized can articulate their lived experience of harm without persistent reference to the notion of 'crime.'” (PEMBERTON, 2007, p.33)

14 ZAFFARONI, E. R. (2007), Un replanteo epistemológico en Criminología (a propósito del libro de Wayne Morrison). ACIPAL, Academia de Ciencias Penales de América Latina.

${ }^{15}$ Alejandro Piombo fez a tradução do inglês para o castelhano desde o México; Raúl Zaffaroni assinou a apresentação; os editores da obra em castelhano, Camilo Bernal, Alejandro Forero, Iván Vidal, Sebastián Cabezas e Iñaki Rivera Beiras introduziram o livro com um precioso Estudo Preliminar e Wayne Morrison escreveu um Epílogo especialmente para a edição castelhana, pensando no leitor ibero-americano.

16 “[...] ¿por qué una disciplina cuyo logos es justamente el estudio del crimen solo había vivido persiguiendo al ladrón y a las infracciones menores descuidando justamente a los grandes procesos de victimización y dejando en la total invisibilidad (léase, impunidad) a los grandes perpetradores del mal extremo? $\mathrm{Y}$, finalmente, ¿tenía algo que decir esa Criminología respecto del convulso 
[...] Por que uma disciplina cujo objeto é justamente o estudo do crime só viveu perseguindo o ladrão e as infrações menores, descuidando justamente dos grandes processos de vitimização e deixando na total invisibilidade (leiase, impunidade) os grandes perpetradores do mal extremo? E, finalmente, tinha algo a dizer essa Criminologia a respeito do convulso presente; se poderia falar de uma Criminologia própria da globalização? (RIVERA BEIRAS, 2014, p. 7-8).

A tese central da obra de Morrison é o estudo do genocídio e como foi ele totalmente desconsiderado pelos saberes criminológicos tradicionais. A partir dessa constatação, Morrison propõe a necessidade de uma Criminologia Global, uma Criminologia própria de um mundo globalizado. Questiona o papel da Criminologia nos diversos crimes massivos de Estado ocorridos desde meados do século XIX até nossos dias, que discurso apresentou diante dos grandes massacres da história, por que permitiu a naturalização e banalização da violência coletiva, por que deixou de criticar e refletir sobre os danos sociais gerados pelas políticas de colonização, as guerras de agressão, os totalitarismos, as atrocidades das ditaduras, mantendo-se em seu papel de denúncia moral, incapaz de desenvolver ferramentas para explicá-las e preveni-las.

Como explicaram Bernal Sarmiento, Cabezas, Forero, Rivera e Vidal (2014, p. 72) no estudo preliminar com o qual apresentaram a tradução do livro ao castelhano, a partir do estudo de Morrison acabou-se por reconhecer que a Criminologia, na verdade, desprezou o estudo da atrocidade massiva durante décadas, deixou de lado as manifestações de violência coletiva que permitiram o cometimento de crimes internacionais, o exercício descontrolado dos poderes político e econômico que facilitaram a criminalidade dos poderosos e a prática de múltiplos crimes por parte dos mercados no âmbito global.

A obra de Morrison foi ponto de partida para um debate muito profícuo que se iniciou na Universidade de Barcelona e que segue até hoje.

Depois da tradução da obra de Morrison, Iñaki Rivera Beiras, Héctor Silveira, Roberto Bergalli e Alejandro Forero realizaram, como parte das atividades do OSPDH, na Universidade de Barcelona, o Seminário "Memória e Filosofia do Mal", no qual participaram também Sebastian Scheerer (do Instituto de Criminologia da Universidade de Hamburgo), Luigi Ferrajoli (da Universidade de Roma III) y Reyes Mate (do CSIC de Madrid), prosseguindo na discussão levantada a partir da obra de Morrison, agora examinando os temas pela categoria da Memória. Além disso, o debate foi levado à Revista eletrônica do

presente; podía hablarse de una Criminología propia de la globalización? [...]" (RIVERA BEIRAS, 2014, p. 7-8). 
OSPDH, "Crítica Penal y Poder", que dedicou ao "dano social” (social harm) uma edição especial $^{17}$ (RIVERA BEIRAS, 2014, p. 8-11).

Quando foi publicada a edição castelhana da obra de Morrison, os editores organizaram sua apresentação pública na Faculdade de Direito da Universidade de Barcelona e, em setembro de 2012, reuniram o próprio Wayne Morrison, Raúl Zaffaroni e Roberto Bergalli para o debate que a obra promovia, a quem se somou, depois, Luigi Ferrajoli. O resultado desses encontros e todas as discussões que incentivaram entre os investigadores do OSPDH foram, então, publicados no livro “Delitos de los Estados, de los Mercados y daño social. Debates en Criminología crítica y Sociología jurídico-penal".

Tratava-se de dar continuidade à discussão sobre essa "nova" Criminologia, reconhecendo que os referentes em que se basearam a Criminologia Crítica permaneciam os mesmos, as categorias de poder e seletividade do sistema penal continuavam vigentes, mas os problemas se estavam modificando, com um incremento evidente do dano social produto da globalização econômica, que deveria ser examinado a partir dos dois grandes produtores de sofrimento: o Estado e as grandes corporações internacionais, voltando o enfoque à criminalidade do Poder" (RIVERA BEIRAS, 2014, p. 5-6).

Como sintetiza Ferrajoli ${ }^{18}$ (2014, p. 94), em texto publicado no livro "Delitos de los Estados, de los Mercados y daño social", a Criminologia deve:

[...] assumir como objeto privilegiado da investigação a criminalidade de poder, quer seja tratada ou não tratada pelo direito penal e, sobretudo, se não for tratada pelo direito penal. Quanto aos crimes de poder previstos no ordenamento como delito, a relação da criminologia com o direito penal deve ser de crítica, a fim de buscar a reversão da via dupla que faz que a justiça penal seja uma justiça fortemente classista: direito penal máximo, maximamente duro e inflexível contra a delinquência dos pobres, delinquência de subsistência; direito penal mínimo, maximamente leve e indulgente contra os crimes de poder, a corrupção, as falências, incluindo a agressão e a violência da polícia contra os manifestantes.

17 Número 7, de 2014, <http://revistes.ub.edu/index.php/CriticaPenalPoder/issue/view/975>. Acesso em 15/04/2017.

18 "[...] que una criminología progresista y científicamente a la altura de la actual globalización autónoma del derecho penal en el doble sentido que no todos los delitos son crímenes y no todos los crímenes son delitos - no sólo debe tematizar, sino asumir como objeto privilegiado de la investigación la criminalidad del poder, ya sea tratada o no tratada por el derecho penal y, sobre todo, si no es tratada por el derecho penal. En cuanto a los crímenes del poder previstos en nuestro ordenamiento como delito, la relación de la criminología con el derecho penal debe ser de crítica, a fin de buscar la reversión de la doble vía que hace hoy a la justicia penal una justicia fuertemente clasista: derecho penal máximo, máximamente duro e inflexible contra la delincuencia de los pobres, delincuencia de subsistencia; derecho penal mínimo, máximamente leve e indulgente contra los crímenes del poder, la corrupción y las bancarrotas, incluyendo la agresión y la violencia de la policía contra los manifestantes." (FERRAJOLI, 2014, p. 94)

Revista Publicum

Rio de Janeiro, v. 3, n. 1, 2017, p. 190-208.

http://www.e-publicacoes.uerj.br/index.php/publicum

DOI: $10.12957 /$ publicum.2017.28920 
Deve, assim, a Criminologia ampliar seu horizonte à criminalidade global, aos crimes de Estado e aos crimes dos mercados, aos crimes de lesa humanidade e àqueles que consistem em violações gravíssima dos direitos humanos.

Para tanto, FERRAJOLI ${ }^{19}$ (2014, p. 94-96) identifica dois papéis que a Criminologia Crítica, assim refundada, deve ter:

a) o papel cognitivo de "análise conceitual dos diversos tipos de crimes de poder e a investigação empírica sobre sua variedade fenomenológica: sobre os gigantescos massacres e sobre os incalculáveis danos provocados por estes; sobre suas causas estruturais e sobre a rede complexa de suas cumplicidades e coalisões; sobre os mecanismos que eliminam estes crimes de poder do horizonte da política, inclusive progressista e do senso comum; sobre o caráter criminal e criminógeno das agressões às pessoas de carne e osso prejudicadas pelas políticas públicas e pelas práticas de mercado"; e

b) o papel crítico e propositivo de "promover uma grande série de políticas e de medidas: em primeiro lugar, a reformulação da hierarquia dos bens jurídicos merecedores de tutela penal, sobre a base da primazia associada à garantia dos direitos constitucionalmente estabelecidos e o grau de ofensa produzidos a eles por diversos tipos de criminalidade; em segundo lugar, e consequentemente, a máxima redução da esfera de intervenção penal frente aos delitos privados de ofensividade ou de escassa ofensividade, também para permitir sua extensão a aqueles maximamente ofensivos aos direitos fundamentais; em terceiro lugar, o desenvolvimento de regras, controles e garantias não penais capazes de submeter ao direito os poderes atualmente selvagens de caráter

${ }^{19} \mathrm{El}$ primer rol, el cognitivo, consiste evidentemente en el análisis conceptual de los diversos tipos de crímenes del poder y en la investigación empírica sobre su variedad fenomenológica: sobre las gigantescas masacres y sobre los incalculables daños provocados por éstas; sobre sus causas estructurales y sobre la red compleja de sus complicidades y colusiones; sobre los mecanismos que eliminan a estos crímenes del poder del horizonte de la política, incluso progresista y del sentido común; sobre el carácter criminal y criminógeno de sus agresiones a las personas de carne y hueso, dañadas por las políticas públicas y por las prácticas de mercado. El segundo rol, crítico y proyectual, consiste en la promoción de una larga serie de políticas y de medidas: en primer lugar, la reformulación de la jerarquía de los bienes jurídicos merecedores de tutela penal, sobre la base de la primacía asociada a la garantía de los derechos constitucionalmente establecidos y del grado de ofensa producidos a estos por diversos tipos de criminalidad; en segundo lugar, $y$ consiguientemente, la máxima reducción de la esfera de intervención penal frente a los delitos privados de ofensividad o de escasa ofensividad, también para permitir su extensión a aquellos máximamente ofensivos de los derechos fundamentales; en tercer lugar, el desarrollo de reglas, de controles y garantías no penales capaces de someter al derecho los poderes actualmente salvajes de carácter supranacional; en cuarto lugar, la formación en la opinión pública de un nuevo sentido común, que identifique aquellas que la tradición reaccionaria de la criminología llamaba las «clases peligrosas", no ya con los sujetos débiles y subordinados, que son hoy los únicos tratados por la justicia y la ejecución penal, sino con los grupos fuertes y los poderes salvajes y desregulados, sean éstos públicos y privados. (p. 94-96) 
supranacional; em quarto lugar, a formação da opinião pública de um novo senso comum, que identifique como aquelas que a tradição reacionária da criminologia chamava de "classes perigosas", não mais os sujeitos fracos e subordinados, que são hoje os únicos tratados pela justiça e pela execução penal, mas os grupos fortes e os poderes selvagens e desregulados, sejam estes públicos ou privados."

\section{Conclusão}

A intenção desse impulso rumo à Criminologia Global é clara: recuperar as bases fundacionais do pensamento crítico sobre a questão criminal e renovar o compromisso com a justiça social.

Para isso, propõe-se um passo para além da criminologia, através da análise dos danos sociais e da criminalidade com a incorporação dos conhecimentos e ferramentas teóricas de várias disciplinas, incluídas aí a própria Zemiologia, rompendo o que Bernal Sarmiento et al. (2014, p. 72) chamam de "aprisionamento e cegueira analítica" da Criminologia.

Em seguida, por meio da abertura de seu horizonte cognoscitivo, a Criminologia deve deixar de olhar para os crimes menores e passar a estudar os danos sociais de grande impacto, desde a perspectiva da criminalidade de poder. Ainda nas palavras de Bernal Sarmiento et al. (2014, p. 72): "Talvez se corra o risco de que se percam os confins clássicos da criminologia nesta tarefa de encontrar-lhe um novo rumo; talvez isso implique ganhar um espaço disciplinar mais cômodo para recuperar a dignidade dos seres humanos frente ao poder e à atrocidade". ${ }^{20}$

O debate aberto nessa direção acena com uma interessante possibilidade de, realmente, permitir o rompimento dos limites epistemológicos da Criminologia Crítica, de despertá-la da inércia e de sua cristalização e de fazer com que o criminólogo crítico retome o projeto político e o ativismo que lhe é inerente, sobretudo na América Latina, em defesa dos direitos humanos.

20 "Quizás se corra el riesgo de que se pierdan los confines clásicos de la criminología en esta tarea de encontrarle un nuevo rumbo; quizás ello implique ganar un espacio disciplinar más cómodo para recuperar la dignidad de los seres humanos frente al poder y la atrocidad." (BERNAL et ali, 2014, p.72). 


\section{Referências}

ANDRADE, Vera Regina Pereira de. Em busca da latinidade criminológica: da recepção da Criminologia Crítica em América Latina à construção da(s) Criminologia(s) Crítica(s) latinoamericana(s) e brasileira(s). In: ZILLIO, Jacson; BOZZA, Fábio. Estudos críticos sobre o sistema penal: homenagem ao Professor Doutor Juarez Cirino dos Santos. Curitiba: LedZe Editora, 2012. p.129-170.

ANITUA, Gabriel Ignacio. Historias de los pensamientos criminológicos. Buenos Aires: Didot, 2015. 584p.

BATISTA, Vera Malaguti. A Escola Crítica e a Criminologia de Juarez Cirino dos Santos. In: ZILLIO, Jacson; BOZZA, Fábio. Estudos críticos sobre o sistema penal: homenagem ao Professor Doutor Juarez Cirino dos Santos. Curitiba: LedZe Editora, 2012. p.117-127.

BERNAL SARMIENTO, Camilo Ernesto, et al. Más Allá de la Criminología. Un Debate Epistemológico sobre el Daño Social, los Crímenes Internacionales y los Delitos de los Mercados. In: RIVEIRA BEIRAS, Iñaki (coord.). Delitos de los Estados, de los Mercados y daño social. Debates en Criminología crítica y Sociología jurídico-penal. Barcelona: Anthropos, 2014. p. 35-80.

BUDÓ, Marília de Nardin. Danos silenciados: a banalidade do mal no discurso científico sobre o amianto. Revista Brasileira de Direito, v.12, n.1, p. 127-140, jan./jun. 2016. DOI: 10.18256/2238-0604/revistadedireito.v12n1p127-140.

CARVALHO, Salo de. Criminologia crítica: dimensões, significados e perspectivas atuais. Revista Brasileira de Ciências Criminais, São Paulo, v.104, p. 279-295, set./out. 2013.

FERREIRA, Carolina Costa. Os Caminhos das Criminologias Críticas; uma revisão bibliográfica. Revista de Criminologias e Políticas Criminais, Curitiba, v.2, n.2, p. 171-192, jul./dez., 2016.

FERRAJOLI, Luigi. Criminología, Crímenes Globales y Derecho Penal. El Debate Epistemológico en la Criminología Contemporánea. In: RIVEIRA BEIRAS, Iñaki (coord.). Delitos de los Estados, de los Mercados y daño social. Debates en Criminología crítica y Sociología jurídico-penal. Barcelona: Anthropos, 2014. p. 81-96

FRIEDRICHS, David O.; SCHWARTZ, Martin D. Editors' introduction: on social harm and a twenty-first century criminology. Crime, Law and Social Change, Netherlands, v. 48, p. 17, out./2007. DOI 10.1007/s10611-007-9080-6.

HIL, Richard; ROBERTSON, Rob. What sort of future for critical criminology? Crime, Law and Social Change, Netherlands, n. 39, p. 91-115, 2003.

HILLYARD, Paddy; TOMBS, Steve. From 'crime' to social harm? Crime, Law and Social Change, v. 48, p. 9-25, out./2007. DOI 10.1007/s10611-007-9079-z.

. ¿MÁS ALLÁ DE LA CRIMINOLOGÍA? Revista Crítica Penal y Poder, Observatorio del

Sistema Penal y los Derechos Humanos, Universidad de Barcelona, n. 4, p. 175-196, 2013. 
MELOSSI, Dario. Overcoming the crisis in critical criminology: toward a grounded labeling theory. Criminology, v. 23, n. 2, p. 193-208, 1985. (Provided by: Universitat de Barcelona. CRAI - Content downloaded/printed from HeinOnline - Wed Apr 5 11:42:59 2017)

MORRISON, Wayne. Criminología, civilización y nuevo orden mundial. Barcelona: Anthropos, 2012. 395p.

PEMBERTON, Simon. Social harm future(s): exploring the potential of the social harm approach. Crime, Law and Social Change, Netherlands, v. 48, p. 27-41, 2007. DOI 10.1007/s10611-007-9078-0.

RIVERA BEIRAS, Iñaki. Hacia una criminología crítica global. Athenea Digital, España, v. 16, n. 1, p. 23-41, 2016. DOI: http://dx.doi.org/10.5565/rev/athenea.1734.

(coord.) Delitos de los Estados, de los Mercados y daño social. Debates en Criminología crítica y Sociología jurídico-penal. Barcelona: Anthropos; OSPDH, 2014. 286p.

La Memoria: Categoría epistemológica para el abordaje de la historia y las ciencias penales. Revista Crítica Penal y Poder, Barcelona: Observatorio del Sistema Penal y los Derechos Humanos, Universidad de Barcelona, n. 1, p. 40-55, 2011.

SWAANINGEN, René Van. Reclaiming Critical Criminology: social justice and the European tradition. Theoretical Criminology, London, v. 3, n. 1, p. 5-28, 1999.

; TAYLOR, lan. Rethinking Critical Criminology - A panel discussion. Crime, Law \& Social Change, Netherlands, n. 21, p. 183-190, 1994.

TIERNEY, John. Criminology - Theory and Context. 2ed. Harlow: Pearson Longman, 1996, 2006. 401p.

Enviado em: 27/05/2017

Aprovado em: 05/08/2017 